\title{
Underlying Mechanisms of Cardiovascular Disease in Chronic Obstructive Pulmonary Disease
}

\author{
William MacNee, MBChB, MD, FRCP ${ }^{1}$ and John D. Maclay, MBChB, MD, MRCP2 \\ ${ }^{1}$ Centre for Inflammation Research, Edinburgh University, Edinburgh, Scotland, UK; ${ }^{2}$ Glasgow Royal Infirmary, Glasgow, Scotland, UK
}

\section{ABSTRACT}

Chronic obstructive pulmonary disease is a lung condition characterized by persistent airflow limitation and is associated with several extrapulmonary manifestations and comorbidities. Cardiovascular diseases are among the most frequent comorbid conditions affecting patients with chronic obstructive pulmonary disease and contribute significantly to the severity, morbidity, and mortality.

Chronic obstructive pulmonary disease shares common risk factors with cardiovascular diseases (i.e. smoking, low socioeconomic class, sedentary lifestyle). However, alternative mechanisms are involved in the pathogenesis of cardiovascular disease that may have a role in driving the increased cardiovascular risk associated with chronic obstructive pulmonary disease. In this manuscript we will discuss the potential mechanisms that link chronic obstructive pulmonary disease to an increased risk of cardiovascular disease. (BRN Rev. 2016;2:69-81) Corresponding author: William MacNee,w.macnee@ed.ac.uk

Key words: Ageing. Atherosclerosis. Inflammation. Pathogenesis. 


\section{INTRODUCTION}

Chronic obstructive pulmonary disease (COPD) is a lung disease that is characterized by persistent airflow limitation that is usually progressive and associated with an enhanced chronic inflammatory response in the airways and the lung to noxious particles or gases ${ }^{1}$. Like many chronic inflammatory conditions, COPD is associated with extrapulmonary effects and comorbidities that contribute to the overall severity in individual patients. Among these there is an association between COPD and cardiovascular disease (CVD). Cardiovascular disease contributes significantly to the morbidity and mortality in COPD ${ }^{2}$.

The mechanism responsible for the increased risk of CVD in patients with COPD is not known; however, a number of mechanisms have been proposed, which will be discussed in this review.

\section{EPIDEMIOLOGIC LINK BETWEEN COPD AND CARDIOVASCULAR DISEASE}

In the Evaluation of COPD Longitudinally to Identify Predictive Surrogate Endpoints (ECLIPSE) study there was an increased prevalence of cardiovascular comorbidities, including hypertension, angina, stroke, heart failure, and arrhythmias in patients with COPD compared to smokers and non-smokers with normal lung function ${ }^{3}$. In a large cohort of COPD patients from the Veterans Administration service, coronary artery disease (CAD) had a prevalence of $33.6 \%$ compared with $27.1 \%$ in a matched cohort without $\mathrm{COPD}^{4}$. Population studies have shown that airflow limitation as measured by forced expiratory volume in 1 second $\left(\mathrm{FEV}_{1}\right)$ is a predictor of cardiovascular risk ${ }^{5}$. Even a moderate reduction in $\mathrm{FEV}_{1}$ increases the risk of morbidity and death and increases cardiovascular events by two to three times ${ }^{6,7}$. In the Lung Health Study in 5,887 patients with COPD with mild-to-moderate airflow limitation, for every $10 \%$ decrease in $\mathrm{FEV}_{1}$ there was an increase of $28 \%$ in fatal and $20 \%$ in nonfatal coronary events ${ }^{8}$. In the National Health Interview Survey of 18,342 individuals over 40 years of age, the presence of COPD increased the odds of CVD by $2.7^{7}$. The Atherosclerosis Risk in Communities (ARIC) population study with 14 years follow-up showed an increase in prevalence of cardiovascular events in individuals with COPD in comparison to controls?.

However, the relative risks were markedly reduced after adjusting for covariates that included traditional cardiovascular risk factors in contrast to the majority of studies of cardiovascular risk in COPD, suggesting that this comorbid condition may be mediated by the high prevalence of traditional risk factors in COPD.

If the enhanced development of atheroma in COPD is a cause of increased cardiovascular risk in COPD, we would expect that patients with COPD would have increased atherosclerotic plaque burden, and indeed carotid intimal thickening as a measure of atherosclerotic plaque burden is increased in smokers with airflow limitation compared to those without ${ }^{10}$ (Fig. 1). In another study of patients with established vascular disease, COPD was associated with increased carotid intimal thickening in those with COPD and was associated with cardiovascular and all-cause mortality ${ }^{11}$. 

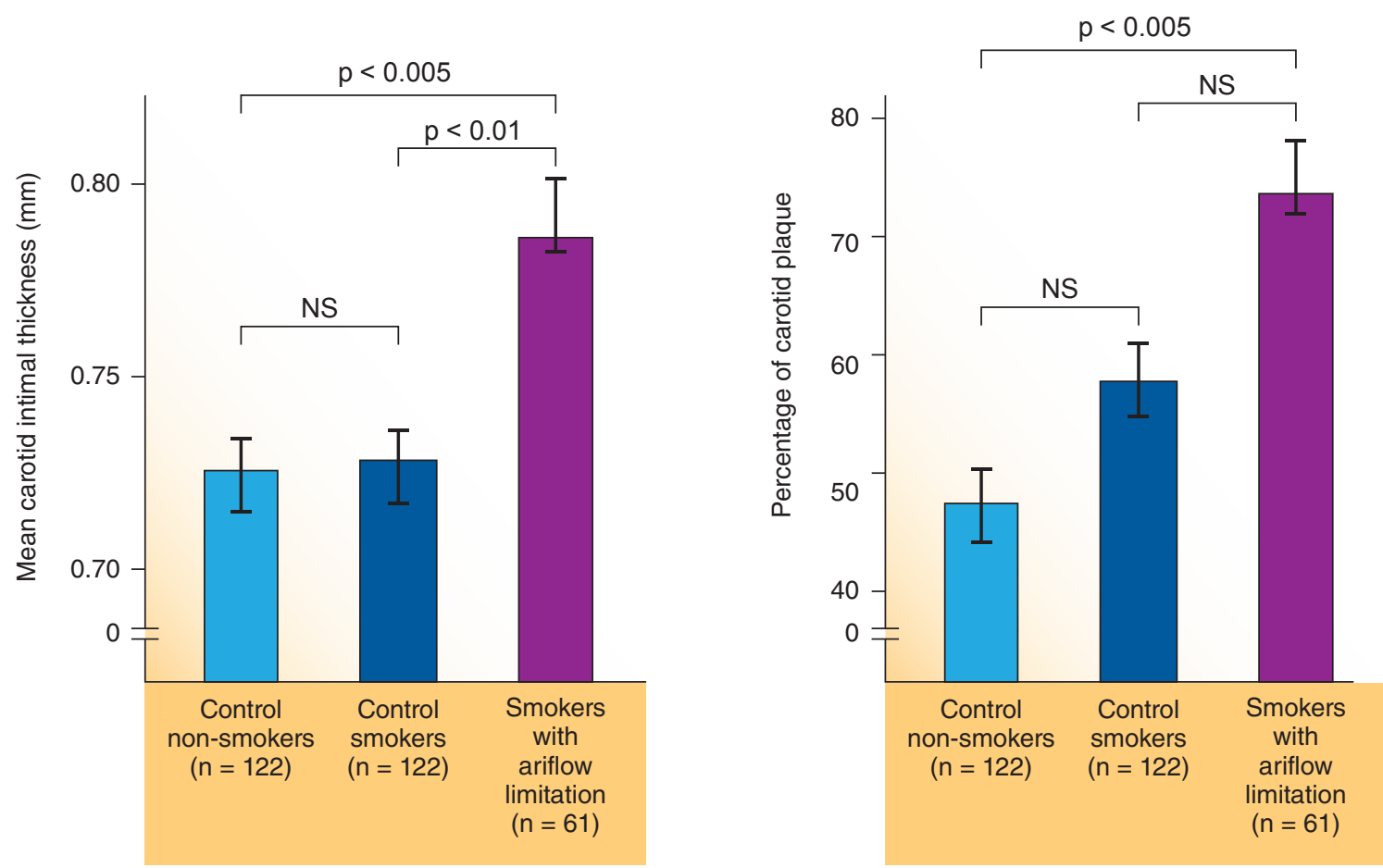

Figure 1. Mean carotid intima-media thickness values are increased in smokers with airflow limitation compared with control neversmokers $(\mathrm{p}<0.005)$ and control smokers $(\mathrm{p}<0.01)$. Error bars indicate $95 \%$ confidence intervals (Iwamoto et al. ${ }^{10}$. Reproduced with permission from American Thoracic Society. Copyright (C) 2015 American Thoracic Society. The American Journal of Respiratory and Critical Care Medicine is an official journal of the American Thoracic Society).

NS: not significant

Systemic arterial stiffness is another measure of cardiovascular risk and is increased in COPD patients compared to non-smokers and smokers with normal lung function, after correction for smoking history ${ }^{12}$ (Fig. 2 A). Arterial stiffness is associated with emphysema, independent of other factors such as smoking history $^{13}$ (Fig. 2 B), suggesting that COPD constitutes an independent risk for CAD.

Cardiovascular disease is a leading cause of death in patients with COPD. In the Lung Health Study, 25\% of COPD subjects died of a cardiovascular event ${ }^{8}$. In the ECLIPSE cohort, the probability of survival was markedly reduced in those patients with cardiovascular comorbidities $^{3}$. In the same cohort, the extent of coronary artery calcification as a measure of the extent of CAD was significantly higher in COPD patients compared with smokers or non-smokers without COPD, and was an independent risk factor for mortality (Fig. 3) ${ }^{14}$.

Thus, a range of population studies and studies in patients with COPD indicate that COPD is an important risk factor for ischaemic heart disease and death from a cardiovascular cause. 


\section{POTENTIAL MECHANISMS}

\section{Shared risk factors}

COPD shares common risk factors with CAD. Cigarette smoking is the most important established risk factor for COPD and is also a risk factor for CAD. Since smoking and COPD are inextricably linked, it is difficult, in a COPD population, to show that the increased risk of CVD in COPD is due to COPD itself. It is likely that cigarette smoke contributes to the development of CVD in COPD. However, carotid intimal medial thickness, a measure of atherosclerotic plaque burden, is increased in smokers with chronic airflow limitation compared to matched smokers and non-smokers without airflow limitation ${ }^{10}$. In addition, arterial stiffness, a risk factor for cardiovascular events, is also increased in COPD patients independent of smoking history ${ }^{13}$. This suggests that smokers with COPD have evidence of increased atherosclerotic burden independent of cigarette smoking.

Other risk factors for ischaemic heart disease are common in COPD patients, such as an increased prevalence of diabetes and hypertension $^{15}$. Since hyperlipidaemia is not more prevalent in COPD patients, the increased cardiovascular risk in COPD is less likely to be attributed to an atherogenic lipid pattern ${ }^{16}$.

Several features of COPD can be associated with increased cardiovascular risk, such as gas exchange abnormalities, polycythaemia, systemic inflammation, lung hyperinflation, and a sedentary lifestyle.

Physical inactivity is a known risk factor for $\mathrm{CVD}^{17}$. Inactivity is also a risk factor for the
A

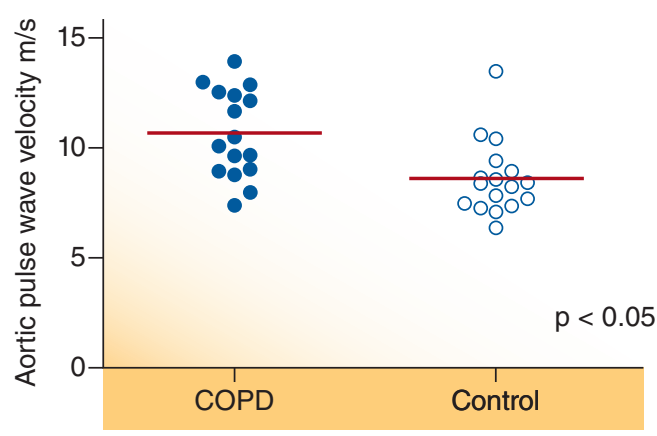

B

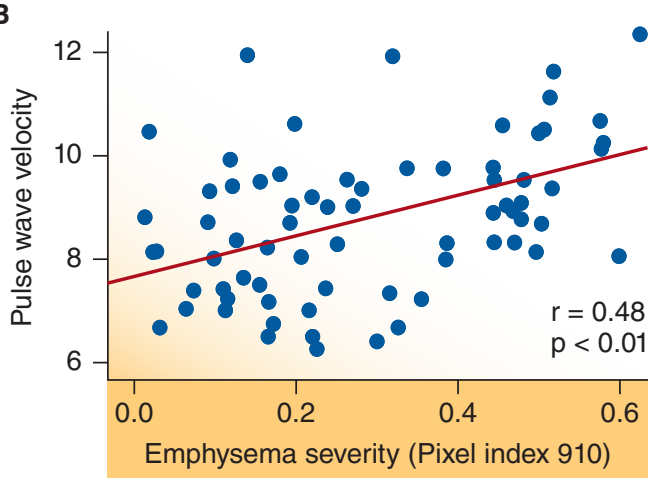

Figure 2. A: patients with chronic obstructive pulmonary disease (COPD) have increased arterial stiffness (aortic pulse wave velocity) compared with matched controls. Symbols represent individual values and the horizontal lines the means. B: association between arterial stiffness (pulse wave velocity) and emphysema severity (pixel index 910) (Maclay et al..$^{12}$ and McAllister et al. ${ }^{13}$. Reproduced with permission from American Thoracic Society. Copyright (C) 2015 American Thoracic Society. The American Journal of Respiratory and Critical Care Medicine is an official journal of the American Thoracic Society).

development of $\mathrm{COPD}^{18}$. A cohort of smokers who had moderate-to-high levels of physical activity had lower lung function decline, and consequently a lower risk of developing COPD, than in those who were inactive ${ }^{19}$. Physical activity is markedly reduced in patients with 


$\begin{array}{lcccc} & \text { COPD } & \text { Smoker controls } & \text { Non-smoker controls } & p \text { value } \\ \mathrm{n} & 676 & 199 & 71 & \\ \mathrm{FEV}_{1} \% \text { pred } & 48.7 \pm 16.1 & 110 \pm 11.5 & 114.4 \pm 13.8 & <0.001 \\ \text { Agatson score } & 415 \pm 689 & 142 \pm 396 & 67 \pm 229 & <0.001\end{array}$

Adjusted for age, gender and pack years

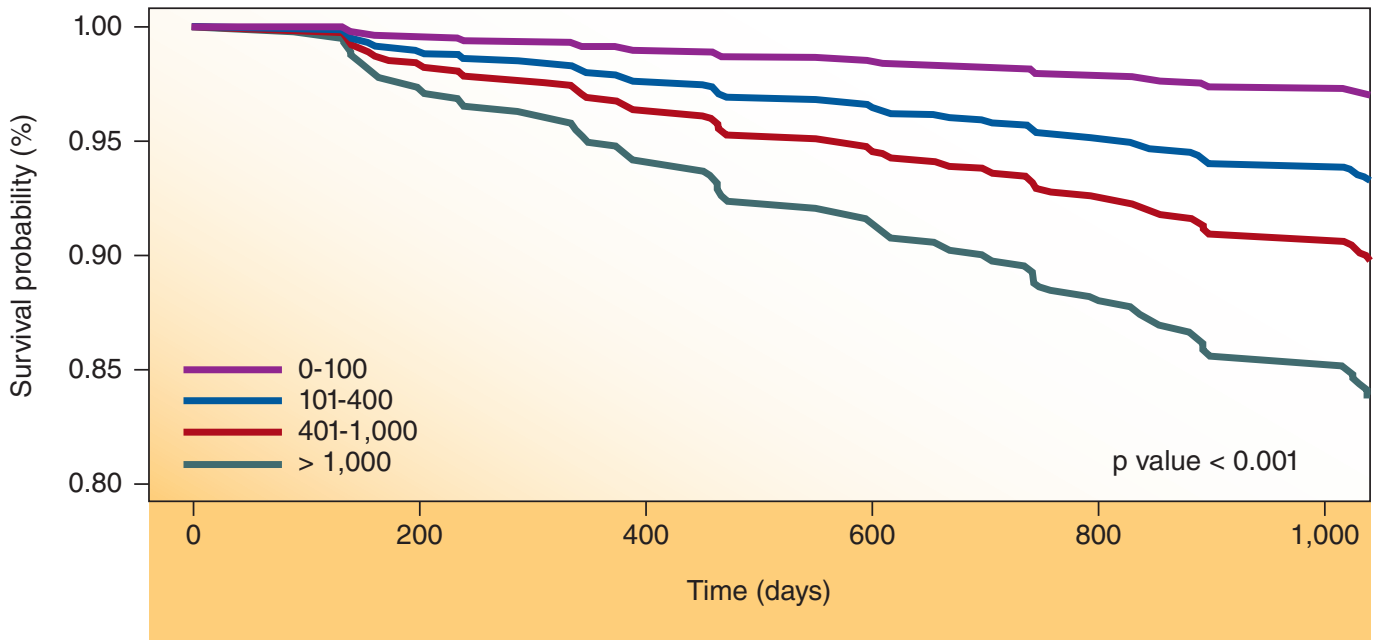

Figure 3. Coronary artery calcification (CACS; Agatston score) is greater in COPD patients than in smoking and non-smoking control subjects. CACS is related to survival in COPD. Cox proportional hazards model for patients with COPD and coronary artery calcium score (CACS; Agatston score) adjusted for age, gender, pack-years, severity of COPD, and self-reported cardiovascular disease (reproduced with permission from Williams et al. ${ }^{14}$. (C) BMJ 2015).

COPD: chronic obstructive pulmonary disease; $\mathrm{FEV}_{1}$ : forced expiratory volume in one second

COPD and is an independent predictor of risk of hospitalizations and mortality in $\mathrm{COPD}^{19}$.

Regular physical activity has been associated with an improvement in endothelial function, has anti-inflammatory effect, reduces body weight, fat mass and circulating lipids, the metabolic cost of activities, and improves insulin sensitivity and angiogenesis and increases the resistance of myocardial cells to ischemia ${ }^{19}$.

Reduced physical activity levels, a feature of COPD, may be one factor accounting for the higher risk of cardiovascular morbidity in patients with COPD.

\section{Systemic inflammation}

COPD is associated not only with pulmonary but also systemic inflammation. A systematic review showed that a range of systemic inflammatory markers, including blood leukocyte count, $\mathrm{C}$ reactive protein (CRP), interleukin-6 (IL-6), and fibrinogen, were elevated in COPD patients compared with smoking controls ${ }^{20}$. Systemic inflammation may contribute to the extrapulmonary features associated with COPD such as an increased risk of $\mathrm{CVD}^{21}$.

However, recent studies indicate that sustained systemic inflammation occurs in only 
some COPD patients $^{22}$, and its relationship to the development of CVD has not been fully established, although patients with COPD and comorbid CVD tend to have higher systemic levels of biomarkers, such as IL-6 and fibrinogen, than those without this comorbidity ${ }^{23}$.

COPD is associated with exacerbations during which systemic inflammation is often further enhanced ${ }^{24}$. As part of this inflammatory response, platelet-monocyte aggregates increase during exacerbations of $\mathrm{COPD}^{25}$ and may represent one mechanism by which inflammation may enhance cardiovascular risk in COPD. Studies also indicate that an elevated troponin $\mathrm{T}$ during exacerbations of COPD, indicating cardiac injury, is associated with an increased risk of death following exacerbation $^{26}$. It is well established that markers of systemic inflammation predict future cardiovascular events ${ }^{27}$.

Most serum proteins are secreted by non-pulmonary organs, such as the liver and the bone marrow, and therefore have only an indirect link to the lung inflammation in COPD. However, pulmonary and activation-regulated chemokine (PARC)/CC-chemokine ligand-18 (CCL-18) is a protein that is constitutively expressed by monocytes/macrophages and dendritic cells and is secreted predominantly in the lungs and is present in blood at higher levels in COPD than in smokers or non-smokers without $\mathrm{COPD}^{28}$. Although the biological role of PARC/CCL-18 is not known, serum levels are elevated in acute coronary syndromes ${ }^{29}$. In addition, elevated PARC/CCL-18 levels were associated with increased risk of cardiovascular hospitalization and mortality in COPD patients ${ }^{28}$.
The mechanisms by which systemic inflammation plays a role in the pathogenesis of CVD are complex. However, inflammation is an important aspect of atherosclerotic plaque initiation, development, and rupture ${ }^{30}$. Atherosclerosis starts with injury to the vascular endothelium due to a variety of factors, including systemic inflammation and oxidative stress increasing endothelial permeability enabling lipoproteins to enter the intima. Systemic oxidative stress and inflammation and modified lipoproteins induce cytokine production and increase the expression of cell adhesion molecules, such as inter-cellular adhesion molecule-1 (ICAM-1) and vascular cell adhesion protein-1 (VCAM-1), on the vascular endothelium, allowing circulating leukocytes to adhere to damaged endothelium. Chemotaxins direct migration of these leukocytes to the vascular intima. There is increased expression of scavenger receptors on monocytes/macrophages that ingest modified lipid lipoprotein particles, promoting the development of foam cells. This is followed by the proliferation of vascular smooth muscle cells that migrate from the media into the intima. These muscle cells produce extracellular matrix, which accumulates in the plaque with the formation of fibro-fatty lesions, resulting in vessel wall fibrosis and consequent smooth muscle cell death. Calcification may occur, resulting in a plaque with a fibrous cap surrounding a lipid-rich core.

A number of cells and molecules can both promote and amplify this inflammatory process. Activated T-lymphocytes and macrophages can stimulate the release of cytokines, resulting in endothelial activation. Cytokines such as IL-1, IL-6, and tumour necrosis factor alpha (TNF- $\alpha$ ) can facilitate the deposition of 
components of atheromatous plaque formation. C-reactive protein (CRP) produced by hepatocytes stimulated by IL-6 is released after vascular damage; it can upregulate other inflammatory cytokines, activate complement, and promote the uptake of low-density lipoproteins by macrophages. C-reactive protein also interacts with endothelial cells to stimulate the production of IL- 6 and endothelin-1 ${ }^{31}$. It may adversely affect vasomotor endothelial function through the inhibition of endothelial nitric oxide synthase and consequently the production of nitric oxide (NO).

Endothelial fibrinolysis is also impaired by CRP, which induces the production plasminogen activator inhibitor-1 (PAI-1), an inhibitor of tissue plasminogen activator ${ }^{32}$. A number of other inflammatory biomarkers have also been implicated in plaque formation, such as IL-6, IL-8, and fibrinogen ${ }^{33}$.

Direct evidence of inflammation has been shown in the vascular wall of the aorta on ${ }^{18} \mathrm{~F}$ fludeoxyglucose (FDG) positron emission tomography imaging and has been shown to be increased in COPD patients compared with smoking controls ${ }^{34}$.

Plasma fibrinogen levels are higher in stable COPD patients than in healthy subjects, independent of current smoking ${ }^{35}$. This increase in procoagulant activity in COPD may result from inflammation, triggering coagulation by promoting tissue-factor gene expression in endothelial cells. There is a direct relationship between plasma fibrinogen and the incidence of cardiovascular events in the general population, and higher plasma fibrinogen levels increases the risk of mortality in subjects with COPD. Fibrinogen levels rise further during
COPD exacerbation ${ }^{36}$, when there is increased risk of cardiovascular events ${ }^{37}$.

A number of studies have investigated the expression of cell-surface receptors in COPD. Expression of P-selectin glycoprotein ligand-1 (PSGL-1) has been shown to be greater on the surface of leukocytes from patients with COPD compared with both smoking and non-smoking controls ${ }^{38}$. The PSGL-1 on leukocytes binds to p-selectin on activated platelets, forming platelet-monocyte aggregates. P-selectin is also expressed on endothelial cells, facilitating leukocyte adhesion to the endothelium. Elevated soluble p-selectin levels are associated with increased risk of cardiovascular events in apparently healthy individuals ${ }^{39}$. Soluble p-selectin levels are higher in COPD patients compared to controls ${ }^{40}$. Platelet-monocyte aggregation, a sensitive and specific measure of platelet activation, is increased in healthy smokers and has been implicated as a mechanism by which smoking increases cardiovascular risk ${ }^{41}$. Platelet-monocyte aggregation is also increased in ex-smokers with stable COPD compared to ex-smoking controls and is further increased during exacerbations of COPD ${ }^{25}$. Thus, interactions between inflammatory cells and platelets may play a role in the pathogenesis of vascular events in COPD. Since inflammation is integrally involved in the initiation and progression of $\mathrm{CVD}^{42}$, systemic inflammation, a feature of COPD, may be a mechanism linking COPD to an increased risk of CVD. However, the association between systemic inflammation and poor outcome should be interpreted with caution. Descriptive studies show associations, but do not prove causality. Moreover, the systemic inflammatory response in COPD is complex and may only be a relevant pathogenic mechanism in a portion of patients. 


\section{OXIDATIVE STRESS}

Both pulmonary and systemic oxidative stress are present in COPD patients and are thought to be involved in the pathogenesis of this condition and its comorbidities ${ }^{43}$. Systemic oxidative stress is also thought to be involved in the pathogenesis of $\mathrm{CAD}^{44}$. Several traditional risk factors, including hypertension, hypercholesterolaemia, smoking, and diabetes, are associated with increased production of reactive oxygen species (ROS) from smooth muscle cells and the vascular endothelium. The ROS are involved in the pathogenesis of atherosclerosis by a number of mechanisms: lipid oxidation, upregulation of cell adhesion molecules, apoptosis of endothelium, proliferation of vascular smooth muscle, activation of matrix metalloproteinases, and altered vasomotor activity ${ }^{45}$.

There are no studies that have specifically addressed the involvement of increased oxidative stress in COPD in the development of CVD. Measurement of ROS is problematic and addressing the issue of increased oxidative stress in COPD and its effect on cardiovascular risk is therefore difficult. However, studies suggest that inhaled particulate matter may result in endothelial dysfunction as a result of the effects of ROS on NO and similar mechanisms may be present in $\mathrm{COPD}^{44}$.

\section{Physiological stresses}

COPD patients are subject to hypoxia, either intermittent hypoxia during exercise or exacerbations sustained in patients with severe disease. Hypoxia can influence atherogenesis by increasing systemic inflammation and oxidative stress, upregulating cell adhesion molecules, and inducing haemodynamic stress ${ }^{46-48}$. Hypoxia can also stimulate increased foam cell production $^{7,46}$, upregulate the cellular adhesion molecules ICAM-1 and P-selectin in endothelial cells ${ }^{47}$, increase CRP production ${ }^{48}$, and induce oxidative stress.

Hypoxia also induces haemodynamic stress ${ }^{49}$. In normal subjects, a hypoxic challenge increases heart rate and cardiac index. Hypoxia also reduces renal blood flow and activates the renin-angiotensin system, with consequent increased peripheral vasoconstriction and oxidative stress ${ }^{50}$.

Sympathetic nervous system activation is associated with increased risk of CVD ${ }^{51}$. COPD is associated with sympathetic nervous system activation $^{52}$, which may contribute to the development of CVD. A high resting heart rate, a feature of sympathetic nervous system activation, is an independent risk factor for cardiovascular morbidity and mortality in the general population, and resting tachycardia is common in $\mathrm{COPD}^{52}$. COPD is also associated with reduced heart rate variability ${ }^{53}$, a marker of abnormal cardiac autonomic regulation, which is a predictor of mortality in the elderly ${ }^{54}$.

\section{Abnormal vascular structure and function}

Abnormalities of the vascular wall structure and function are known to predispose to and predict future cardiovascular events and mortality. Several studies have used flow-mediated dilation as a measure of endothelial function in COPD. This technique uses ultrasound to assess the dilation of the brachial artery following arterial occlusion ${ }^{55}$. The subsequent 
reactive hyperaemia is primarily dependent on the release of the vasodilator NO from the endothelium. Impaired flow-mediated dilation is associated with both the severity of airflow limitation and emphysema in a population of former smokers with and without $\mathrm{COPD}^{56}$. It has been shown in patients with COPD compared to healthy controls and smokers with normal lung function ${ }^{57}$, and was associated with the level of impaired lung function and with markers of systemic inflammation including CRP, suggesting that systemic inflammation may play a role in vascular dysfunction in COPD.

Arterial stiffness can be assessed as the carotid-femoral pulse wave velocity (PWV), which measures the speed of the pulse wave across the aorta $^{58}$. Aortic PWV is predictive of cardiovascular events in healthy individuals and is associated with mortality in patients with ischemic heart disease $\mathrm{e}^{59}$. Arterial stiffness is influenced by the structural components of the vessel wall, including the endothelium, the vascular smooth muscle, and the extracellular matrix. There is a relationship between reduced lung function and increased PWV in men free from CVD that is independent of traditional risk factors for CVD such as smoking, hypertension, and hyperlipidaemia $^{60}$. In COPD patients, arterial stiffness is increased compared with matched controls, and was associated with the level of airflow limitation and blood IL-6 and CRP levels ${ }^{61,62}$, suggesting a role for systemic inflammation in the pathogenesis of arterial stiffness in COPD. In a larger cohort of patients with COPD, an independent association between $\mathrm{FEV}_{1}$ and $\mathrm{PWV}$ was confirmed and close association between computed tomography (CT)-measured emphysema severity and arterial stiffness was found after adjusting for traditional risk factors ${ }^{13}$.
To determine the mechanism for the increased arterial stiffness in COPD, a case-control study measured endothelial function and arterial stiffness in patients with COPD and controls well matched for age and cigarette smoke exposure ${ }^{12}$. This study confirmed an increased arterial stiffness in patients with COPD, but found no differences between the groups in two measures of endothelial function: vasomotion (in the resistance vessels of the forearm vascular bed) and the release of the endogenous fibrinolytic tissue plasminogen activator. From these studies it was suggested that the increased arterial stiffness in COPD may be due to abnormalities of extracellular matrix in the arterial wall as a result of elastin degradation that may occur in the lungs, resulting in emphysema, and in the vasculature, giving rise to increased arterial stiffness. Support for this hypothesis comes from a study showing an association between skin wrinkling, suggestive of increased systemic elastin degradation and emphysema severity in a COPD cohort ${ }^{63}$ and from a study showing increased cutaneous elastin degradation in patients with COPD that was associated with both emphysema severity and increased arterial stiffness ${ }^{64}$. Moreover, plasma desmosine, a marker of systemic elastin degradation, is associated with the presence of CVD and has a positive correlation with arterial stiffness in a cohort of COPD patients ${ }^{65}$.

As the elastin in the walls of large vessels is degraded, calcification occurs (medial elastocalcinosis), which is a feature of normal ageing $^{66}$. Emphysema severity as measured by CT scanning has been shown to correlate with thoracic and distal aortic calcification, both in healthy individuals and in those with $\mathrm{COPD}^{67}$. Moreover, aortic calcification has been related 
to measures of arterial stiffness and to mortality in COPD patients ${ }^{68}$.

\section{Protease/antiprotease imbalance}

Protease/antiprotease imbalance is thought to be an important pathogenic mechanism in both COPD and CVD.

Matrix metalloproteinases (MMP) are thought to be important in the pathogenesis of COPD. Expression of MMP-2 protein is increased in peripheral lung tissue and in alveolar macrophages, and its activity was increased in the sputum of COPD patients in comparison with healthy smokers and non-smokers ${ }^{69,70}$. MMP-2 has also been linked with the development of CAD. MMP-2 is increased in atherosclerotic plaques in the aorta ${ }^{71}$ and in coronary atherosclerotic lesions ${ }^{72}$ and increased serum MMP-2 is also associated with increased arterial stiffness ${ }^{73}$.

Matrix metalloproteinase-9 has also been implicated in the pathogenesis of emphysema. The MMP-9 promoter polymorphisms are associated with upper zone predominant pulmonary emphysema ${ }^{74}$. Peripheral blood monocytes from COPD patients show enhanced release of MMP-9 compared with cells from controls $^{75}$ and higher circulating levels of MMP-9 have been shown in COPD patients ${ }^{76}$. MMP-9 has also been implicated in the development of arterial stiffness and atherosclerosis. Atherosclerotic plaques demonstrate increased concentrations of MMP-977. Circulating MMP-9 levels are associated with increased arterial stiffness ${ }^{73}$. In addition, polymorphisms in the MMP-9 gene, which result in higher MMP-9 mRNA expression, protein levels, and MMP-9 activity in vascular tissue, are associated with arterial stiffness ${ }^{73}$.

Upregulation of cutaneous MMP-2 and -9 gene expression has been shown to correlate with skin elastin degradation, which in turn correlates with arterial stiffness ${ }^{64}$. Thus, upregulation of MMPs may also occur in the arteries of COPD patients, resulting in elastin degradation and increased arterial stiffness, and locally increased MMPs in the lungs may result in emphysema, providing a mechanistic link between emphysema and arterial stiffness and hence cardiovascular risk in COPD.

\section{Ageing}

Ageing is among the greatest known risk factors for most chronic diseases. Airspace enlargement and loss of lung elastic recoil (as in emphysema), increased arterial stiffness, and vascular calcification are all features seen in normal ageing ${ }^{78,79}$. Similarities between features of COPD and the ageing lung suggest that COPD may be a condition related to accelerated ageing ${ }^{80}$. Shorter telomeres, a marker of ageing, occur in peripheral blood leukocytes from COPD patients compared with control subjects ${ }^{81}$. Shorter telomeres are also present in cells from emphysematous lungs compared with control lungs ${ }^{82}$. When telomere length reaches a critical value, cell-cycle arrest (senescence) occurs. Cell senescence is the cellular equivalent of ageing. Senescent cells express a different gene profile, including the cell cycle control kinase inhibitors p53, p21, and p16, which are increased in emphysematous lungs compared with the lungs of smokers without $\mathrm{COPD}^{82}$. Cellular senescence can contribute to the pathogenesis of COPD and emphysema by increasing epithelial and 


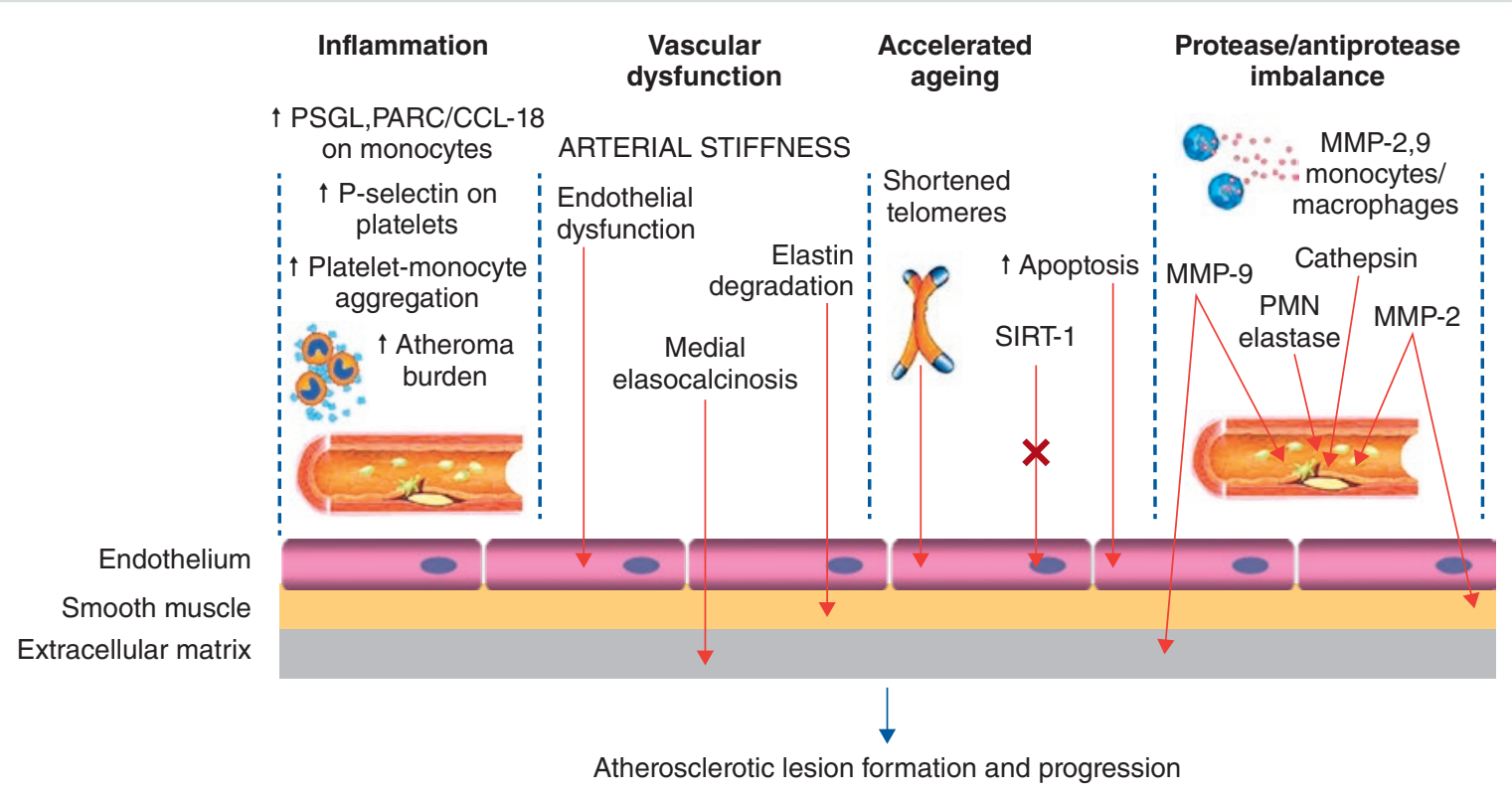

FigurE 4. Putative mechanisms for the pathogenesis of cardiovascular disease in COPD.

MMP: matrix metalloproteinase; PARC/CCL-18: pulmonary and activation-regulated chemokine CC chemokine ligand 18; PSGL: P-selectin glycoprotein ligand-1; SIRT-1: sirtuin 1.

endothelial cell apoptosis, which results in loss of cells in the alveolar walls ${ }^{83,84}$. There is also a relationship between the extent of cellular senescence and the severity of inflammation in emphysema ${ }^{85}$. Metabolic nicotinamide adenine nucleotide-dependent histone/protein deacetylases (sirtuins) have an important role in senescence and ageing ${ }^{86}$. Sirtuin-1 (SIRT-1) has been shown to be reduced in lung cells from COPD patients as a result of post-translational oxidative modification of the molecule and increased acetylation and enhanced inflammatory responses to cigarette smoke ${ }^{87}$.

Accelerated ageing mechanisms are also implicated in the pathogenesis of atherosclerosis.

Endothelial cell senescence is thought to have endothelial dysfunction and atherogenesis ${ }^{88}$.
Shortened leukocyte telomere length has been associated with increased arterial stiffness ${ }^{89}$ and is a predictor of future coronary heart disease events ${ }^{90}$. Furthermore SIRT-1 plays a critical role in endothelial cell homeostasis and may protect against vascular senescence, dysfunction, and atherosclerosis ${ }^{91}$. Thus, mechanisms leading to accelerated ageing in the lungs and in the vasculature may provide a mechanistic link between COPD and vascular dysfunction.

\section{CONCLUSIONS}

A number of putative mechanisms have been proposed that link coronary heart disease and COPD (Fig. 4). Although COPD is associated with a number of measures of cardiovascular risk and with mediators of cardiovascular 
disease, atherosclerosis, and thrombosis, it is as yet unclear whether these markers play a specific role in the pathogenesis or are epiphenomena. Although we are closer to uncovering the causative mechanisms for cardiovascular disease in COPD, more work is required to elucidate these, which should provide novel targets for treatment of both the lung and cardiovascular manifestations of COPD.

\section{REFERENCES}

1. The Global Initiative for Chronic Obstructive Pulmonary Disease. Available at: www.goldcopd.org

2. Holguin F, Folch E, Redd SC et al. Comorbidity and mortality in COPD-related hospitalizations in the United States, 1979 to 2001. Chest. 2005;128:2005-11.

3. Miller J, Edwards LD, Agusti A et al. Comorbidity, systemic inflammation and outcomes in the ECLIPSE cohort. Respir Med. 2013;107:1376-84.

4. Mapel DW, Dedrick D, Davis K. Trends and cardiovascular co-morbidities of COPD patients in the Veterans Administration Medical System, 19911999. COPD. 2005;2:35-41.

5. Sin DD, Man SF. Chronic obstructive pulmonary disease as a risk factor for cardiovascular morbidity and mortality. Proc Am Thorac Soc. 2005;2:8-11.

6. Hole DJ, Watt GC, Davey-Smith G et al. Impaired lung function and mortality risk in men and women: findings from the Renfrew and Paisley prospective population study. BMJ. 1996;313:711-5.

7. Finkelstein J, Cha E, Scharf SM. Chronic obstructive pulmonary disease as an independent risk factor for cardiovascular morbidity. Int J COPD. 2009;4:337-49.

8. Anthonisen NR, Connett JE, Enright PL et al. Hospitalizations and mortality in the Lung Health Study. Am J Respir Crit Care Med. 2002;166:333-9.

9. Johnston AK, Mannino DM, Hagan GW, Davis KJ, Kiri VA. Relationship between lung function impairment and incidence or recurrence of cardiovascular events in a middle-aged cohort. Thorax. 2008;63:599-605.

10. Iwamoto H, Yokoyama A, Kitahara Y et al. Airflow limitation in smokers is associated with subclinical atherosclerosis. Am J Respir Crit Care Med. 2009;179:35-40.

11. van Gestel YR, Flu WJ, van Kuijk J-P et al. Association of COPD with carotid wall intima-media thickness in vascular surgery patients. Respir Med. 2010;104:712-6.

12. Maclay JD, McAllister DA, Mills NL et al. Vascular dysfunction in chronic obstructive pulmonary disease. Am J Respir Crit Care Med. 2009;180:513-20.

13. McAllister DA, Maclay JD, Mills NL et al. Arterial stiffness is independently associated with emphysema severity in patients with chronic obstructive pulmonary disease. Am J Respir Crit Care Med. 2007;176:1208-14.

14. Williams MC, Murchison JT, Edwards LD et al. Coronary artery calcification is increased in patients with COPD and associated with increased morbidity and mortality. Thorax. 2014;69:718-23.

15. Mannino DM, Thorn D, Swensen A et al. Prevalence and outcomes of diabetes, hypertension and cardiovascular disease in COPD. Eur Respir J. 2008;32:962-9.

16. Basili S, Ferroni P, Vieri M et al. Lipoprotein(a) serum levels in patients affected by chronic obstructive pulmonary disease. Atherosclerosis. 1999;147:249-52.

17. Garber CE, Blissmer B, Deschenes MR et al. American College of Sports Medicine position stand. Quantity and quality of exercise for developing and maintaining cardiorespiratory, musculoskeletal, and neuromotor fitness in apparently healthy adults: guidance for prescribing exercise. Med Sci Sports Exerc. 2011;43:1334-59.

18. Oga T, Nishimura K, Tsukino $M$ et al. Analysis of the factors related to mortality in chronic obstructive pulmonary disease: role of exercise capacity and health status. Am J Respir Crit Care Med. 2003;167:544-9.
19. Garcia-Aymerich J, Lange P, Benet M et al. Regular physical activity modifies smoking-related lung function decline and reduces risk of chronic obstructive pulmonary disease: a population-based cohort study. Am J Respir Crit Care Med. 2007;175:458-63.

20. Gan WQ, Man SFP, Senthilselvan A et al. Association between chronic obstructive pulmonary disease and systemic inflammation: a systematic review and a metaanalysis. Thorax. 2004;59:574-80.

21. Agustí A. Systemic effects of chronic obstructive pulmonary disease: What we know and what we don't know (but should). Proc Am Thorac Soc. 2007;4:522-5.

22. Agustí A, Edwards LD, Rennard SI et al. Persistent systemic inflammation is associated with poor clinical outcomes in COPD: a novel phenotype. PloS One. 2012;7:e37483.

23. Celli BR, Locantore N, Yates J et al. Inflammatory biomarkers improve clinical prediction of mortality in chronic obstructive pulmonary disease. Am J Respir Crit Care Med. 2012;185:1065-72.

24. Hurst JR, Donaldson GC, Perera WR et al. Use of plasma biomarkers at exacerbation of chronic obstructive pulmonary disease. Am J Respir Crit Care Med. 2006;174:867-74.

25. Maclay JD, McAllister DA, Johnston S et al. Increased platelet activation in patients with stable and acute exacerbation of COPD. Thorax. 2011;66:769-74.

26. Hoiseth AD, Neukamm A, Karlsson BD et al. Elevated high-sensitivity cardiac troponin $\mathrm{T}$ is associated with increased mortality after acute exacerbation of chronic obstructive pulmonary disease. Thorax. 2011;66:775-81.

27. Ridker P, Rifai N, Rose L et al. Comparison of C-reactive protein and low-density lipoprotein cholesterol levels in the prediction of first cardiovascular events. N Engl J Med. 2002;347:1557-65.

28. Sin DD, Miller BE, Duvoix A et al. Serum PARC/CCL-18 concentrations and health outcomes in chronic obstructive pulmonary disease. Am J Respir Crit Care Med. 2011;183:1187-92.

29. Kraaijeveld AO, de Jager SC, de Jager WJ et al. CC chemokine ligand-5 (CCL5/RANTES) and CC chemokine ligand-18 (CCL18/PARC) are specific markers of refractory unstable angina pectoris and are transiently raised during severe ischemic symptoms. Circulation. 2007;116:1931-41.

30. Libby P, Theroux P. Pathophysiology of coronary artery disease. Circulation. 2005;111:3481-8.

31. Yeh ET, Anderson HV, Pasceri V et al. C-reactive protein: linking inflammation to cardiovascular complications. Circulation. 2001;104:974-5.

32. Venugopal SK, Devaraj S, Yuhanna I et al. Demonstration that C-reactive protein decreases eNOS expression and bioactivity in human aortic endothelial cells. Circulation. 2002;106:1439-41.

33. Luc G, Bard JM, Juhan-Vague I et al. C-reactive protein, interleukin-6, and fibrinogen as predictors of coronary heart disease: the PRIME Study. Arterioscler Thromb Vasc Biol. 2003;23:1255-61.

34. Coulson JM, Rudd JH, Duckers JM et al. Excessive aortic inflammation in chronic obstructive pulmonary disease: an 18F-FDG PET pilot study. J Nucl Med. 2010;51:1357-60.

35. Ashitani J-I, Mukae H, Arimura Y et al. Elevated plasma procoagulant and fibrinolytic markers in patients with chronic obstructive pulmonary disease. Intern Med. 2002;41:181-5.

36. Wedzicha JA, Syndercombe-Court D, Tan KC. Increased platelet aggregate formation in patients with chronic airflow obstruction and hypoxaemia. Thorax. 1991;46:504-7.

37. McAllister DA, Maclay JD, Mills NL et al. Diagnosis of myocardial infarction following hospitalisation for exacerbation of COPD. Eur Respir J. 2012;39:1097-103.

38. Schumacher A, Liebers U, John M et al. P-selectin glycoprotein ligand-1 (PSGL-1) is up-regulated on leucocytes from patients with chronic obstructive pulmonary disease. Clin Exp Immunol. 2005;142:370-6.

39. Ridker PM, Buring JE, Rifai N. Soluble P-selectin and the risk of future cardiovascular events. Circulation. 2001;103:491-5.

40. Ferroni P, Basili S, Martini F et al. Soluble P-selectin as a marker of platelet hyperactivity in patients with chronic obstructive pulmonary disease. J Investig Med. 2000;48:21-7.

41. Harding S, Sarma J, Josephs D et al. Upregulation of the CD40/CD40 ligand dyad and platelet-monocyte aggregation in cigarette smokers. Circulation. 2004;109:1926-9.

42. Libby P, Ridker PM, Maseri A. Inflammation and atherosclerosis. Circulation. 2002;105:1135-43. 
43. MacNee W. Pulmonary and systemic oxidant/antioxidant imbalance in chronic obstructive pulmonary disease. Proc Am Thorac Soc. 2005;2:50-60.

44. Mills NL, Törnqvist H, Robinson SD et al. Diesel exhaust inhalation causes vascular dysfunction and impaired endogenous fibrinolysis. Circulation. 2005;112:3930-6.

45. Elahi MM, Kong YK, Matata BM. Oxidative stress as a mediator of cardiovascular disease. Oxid Med Cell Longev. 2009;2:259-69.

46. Lattimore JD, Wilcox I, Nakhla S et al. Repetitive hypoxia increases lipid loading in human macrophages-a potentially atherogenic effect. Atherosclerosis. 2005;179:255-9.

47. Ichikawa H, Flores S, Kvietys P et al. Molecular mechanisms of anoxia/ reoxygenation-induced neutrophil adherence to cultured endothelial cells. Circulation Res. 1997;81:922-31.

48. Hartmann G, Tschop M, Fischer R et al. High altitude increases circulating interleukin-6, interleukin-1 receptor antagonist and C-reactive protein. Cytokine. 2000;12:246-52.

49. Thomson AJ, Drummond GB, Waring WS et al. Effects of short-term isocapnic hyperoxia and hypoxia on cardiovascular function. J Appl Physiol. 2006;101:809-16.

50. Skwarski K, Morrison D, Barratt A et al. Effects of hypoxia on renal hormonal balance in normal subjects and in patients with COPD. Respir Med. 1998;92:1331-6.

51. Curtis BM, O'Keefe JH. Autonomic tone as a cardiovascular risk factor: the dangers of chronic fight or flight. Mayo Clin Proc. 2002;77:45-54.

52. Heindl S, Lehnert M, Criée CP et al. Marked sympathetic activation in patients with chronic respiratory failure. Am J Respir Crit Care Med. 2001;164:597-601.

53. Volterrani M, Scalvini S, Mazzuero G et al. Decreased heart rate variability in patients with chronic obstructive pulmonary disease. Chest. 1994;106:1432-7.

54. Tsuji H, Venditti FJ, Manders ES et al. Reduced heart rate variability and mortality risk in an elderly cohort. The Framingham Heart Study. Circulation. 1994;90:878-83.

55. Corretti MC, Anderson TJ, Benjamin EJ et al. Guidelines for the ultrasound assessment of endothelial-dependent flow-mediated vasodilation of the brachial artery: a report of the International Brachial Artery Reactivity Task Force. J Am Coll Cardiol. 2002;39:257-65.

56. Barr R, Mesia-Vela S, Austin J et al. Impaired flow-mediated dilation is associated with low pulmonary function and emphysema in ex-smokers: the Emphysema and Cancer Action Project (EMCAP) Study. Am J Respir Crit Care Med. 2007;176:1200-7.

57. Eickhoff P, Valipour A, Kiss D et al. Determinants of systemic vascular function in patients with stable chronic obstructive pulmonary disease. Am J Respir Crit Care Med. 2008;178:1211-18.

58. Laurent S, Cockcroft J, Van Bortel L et al. Expert consensus document on arterial stiffness: methodological issues and clinical applications. Eur Heart J. 2006;27:2588-605.

59. Vlachopoulos C, Aznaouridis K, Stefanadis C. Prediction of cardiovascular events and all-cause mortality with arterial stiffness: a systematic review and meta-analysis. J Am Coll Cardiol. 2010;55:1318-27.

60. Zureik M, Benetos A, Neukirch C et al. Reduced pulmonary function is associated with central arterial stiffness in men. Am J Respir Crit Care Med. 2001;164:2181-5.

61. Sabit R, Bolton CE, Edwards PH et al. Arterial stiffness and osteoporosis in chronic obstructive pulmonary disease. Am J Respir Crit Care Med. 2007; 175:1259-65.

62. Mills NL, Miller JJ, Anand A et al. Increased arterial stiffness in patients with chronic obstructive pulmonary disease: a mechanism for increased cardiovascular risk. Thorax. 2008;63:306-11.

63. Patel BD, Loo WJ, Tasker AD et al. Smoking related COPD and facial wrinkling: is there a common susceptibility? Thorax. 2006;61:568-71.

64. Maclay JD, McAllister DA, Rabinovich R et al. Systemic elastin degradation in chronic obstructive pulmonary disease. Thorax. 2012;67:606-12.

65. Rabinovich R, Miller BE, Wrobel K et al. Evaluation of COPD Longitudinally to Identify Predictive Surrogate Endpoints (ECLIPSE) Investigators. Circulating desmosine levels do not predict emphysema progression but are associated with cardiovascular risk and mortality in COPD. Eur Respir J. 2015.

66. Atkinson J. Age-related medial elastocalcinosis in arteries: mechanisms, animal models, and physiological consequences. J Appl Physiol. 2008;105:1643-51.
67. Dransfield MT, Huang F, Nath $\mathrm{H}$ et al. CT emphysema predicts thoracic aortic calcification in smokers with and without COPD. COPD. 2010;7:404-10.

68. Romme EA, McAllister DA, Murchison JT et al. Associations between COPD related manifestations: a cross-sectional study. Respir Res. 2013, $14: 129$.

69. Baraldo S, Bazzan E, Zanin ME et al. Matrix metalloproteinase-2 protein in lung periphery is related to COPD progression. Chest. 2007;132:1733-40.

70. Cataldo D, Munaut C, Noël A et al. MMP-2- and MMP-9-linked gelatinolytic activity in the sputum from patients with asthma and chronic obstructive pulmonary disease. Int Arch Allergy Immunol. 2000;123:259-67.

71. Li Z, Li L, Zielke HR et al. Increased expression of 72-kd type IV collagenase (MMP-2) in human aortic atherosclerotic lesions. Am J Pathol. 1996;148:121-8.

72. Brown DL, Hibbs MS, Kearney M et al. Identification of 92-kD gelatinase in human coronary atherosclerotic lesions. Association of active enzyme synthesis with unstable angina. Circulation. 1995;91:2125-31.

73. Yasmin, McEniery CM, Wallace S et al. Matrix metalloproteinase-9 (MMP 9), MMP-2, and serum elastase activity are associated with systolic hypertension and arterial stiffness. Arterioscler Thromb Vasc Biol. 2005;25:372.

74. Ito I, Nagai S, Handa T et al. Matrix metalloproteinase-9 promoter polymorphism associated with upper lung dominant emphysema. Am J Respir Crit Care Med. 2005;172:1378-82.

75. Aldonyte R, Jansson L, Piitulainen E et al. Circulating monocytes from healthy individuals and COPD patients. Respir Res. 2003;4:11.

76. Bolton $\mathrm{CE}$, Stone MD, Edwards $\mathrm{PH}$ et al. Circulating matrix metalloproteinase- 9 and osteoporosis in patients with chronic obstructive pulmonary disease. Chron Respir Dis. 2009;6:81-7.

77. Galis ZS, Sukhova GK, Lark MW et al. Increased expression of matrix metalloproteinases and matrix degrading activity in vulnerable regions of human atherosclerotic plaques. J Clin Invest. 1994;94:2493-503.

78. Janssens JP, Pache JC, Nicod LP. Physiological changes in respiratory function associated with ageing. Eur Respir J. 1999;13:197-205.

79. Lee HY, Oh BH. Aging and arterial stiffness. Circ J. 2010;74:2257-62.

80. MacNee W. Accelerated lung aging: a novel pathogenic mechanism of chronic obstructive pulmonary disease (COPD). Biochem Soc Trans 2009;37:819-23.

81. Savale L, Chaouat A, Bastuji-Garin S et al. Shortened telomeres in circulat ing leukocytes of patients with chronic obstructive pulmonary disease. Am J Respir Crit Care Med. 2009;179:566-71.

82. Tsuji T, Aoshiba K, Nagai A. Alveolar cell senescence in patients with pulmonary emphysema. Am J Respir Crit Care Med. 2006;174:886-93.

83. Yokohori N, Aoshiba K, Nagai A. Increased levels of cell death and proliferation in alveolar wall cells in patients with pulmonary emphysema. Chest. 2004;125:626-32.

84. Kasahara Y, Tuder RM, Cool CD et al. Endothelial cell death and decreased expression of vascular endothelial growth factor and vascular endothelia growth factor receptor 2 in emphysema. Am J Respir Crit Care Med. 2001;163:737-44.

85. Amsellem V, Gary-Bobo G, Marcos E et al. Telomere dysfunction causes sustained inflammation in chronic obstructive pulmonary disease. Am J Respir Crit Care Med. 2011;184:1358-66.

86. Sauve AA, Wolberger C, Schramm VL et al. The biochemistry of sirtuins Annu Rev Biochem. 2006;75:435-65.

87. Rajendrasozhan S, Yang SR, Kinnula VL et al. SIRT1, an antiinflammatory and antiaging protein, is decreased in lungs of patients with chronic obstructive pulmonary disease. Am J Respir Crit Care Med. 2008;177:861-70.

88. Minamino T, Miyauchi H, Yoshida T et al. Endothelial cell senescence in human atherosclerosis: role of telomere in endothelial dysfunction. Circulation. 2002;105:1541-4

89. Benetos A, Okuda K, Lajemi M et al. Telomere length as an indicator of biological aging: the gender effect and relation with pulse pressure and pulse wave velocity. Hypertension. 2001;37:381-5.

90. Brouilette SW, Moore JS, McMahon AD et al. Telomere length, risk of coronary heart disease, and statin treatment in the West of Scotland Primary Prevention Study: a nested case-control study. Lancet. 2007;369:107-14.

91. Ota H, Eto M, Ogawa S et al. SIRT1/eNOS axis as a potential target against vascular senescence, dysfunction and atherosclerosis. J Atheroscler Thromb. 2010;17:431-5. 